\title{
An innovative micromechanics-based three-dimensional long-term strength criterion for fracture assessment of rock materials
}

\author{
Xiao-Ping Zhou, Xiao-Cheng Huang \\ School of Civil Engineering, Chongqing University, Chongqing 400045, China \\ State Key Laboratory of Coal Mine Disaster Dynamics and Control, Chongqing University, Chongqing 400044, China \\ Filippo Berto \\ Department of Mechanical Engineering, Norwegian University of Science and Technology, Trondheim 7491, Norway
}

\begin{abstract}
Rocks may exhibit time-dependent behaviors. Long-term strength criterion significantly dominates creep failure of rocks. Rocks contain many microcracks, which lead to degrade of long-term strength. In this paper, it is assumed that there exist three-dimensional penny-shaped microcracks in rocks. The mode II stress intensity factors at tips of three-dimensional pennyshaped microcracks in Burgers viscoelastic rock matrix is derived. A novel micromechanics-based three-dimensional long-term strength criterion is established to consider the effects of time and the intermediate principal stress on creep failure of rocks. By comparison with the previous experimental data, it is found that the novel micromechanics-based threedimensional long-term strength criterion is in good agreement with the experimental data.
\end{abstract}

KEYWORDS. Micromechanics-based three-dimensional long-term strength criterion; Burgers viscoelastic rock matrix; three-dimensional penny-shaped creep microcracks; Stress intensity factor; The intermediate principal stress.

\section{OPEN ACCESS}

Citation: Zhou, X.-P., Huang, X.-C., Berto, F., An innovative micromechanics-based three-dimensional long-term strength criterion for fracture assessment of rock materials, Frattura ed Integrità Strutturale, 44 (2018) 64-81.

Received: 19.01.2018

Accepted: 05.02.2018

Published: 01.04.2018

Copyright: (C) 2018 This is an open access article under the terms of the CC-BY 4.0, which permits unrestricted use, distribution, and reproduction in any medium, provided the original author and source are credited.

\section{INTRODUCTION}

I $\mathrm{n}$ the past several decades or more, extensive laboratory creep experiments were conducted to study the creep behaviors of many kinds of rocks [1-5]. It is indicated that deformation of rocks under a constant load over extended a period of time generally exhibits primary or transient creep, lately by secondary or steady-rate creep, followed terminating in tertiary or accelerating creep that eventually progresses to dynamic rupture. Moreover, it is observed from laboratory creep experiments that the failure of rocks occurs at stresses well below the peak strength of rocks. Analyses that the short-term strength is applied to estimate the stability of the surrounding rock mass around tunnels have often predicted stable openings even though the failure of rock mass is observed in situ. For example, it is observed that the long-term strength of rock in situ can be as low as $50 \%$ of the short-term strength [6]. 
To investigate the long-term strength of rock, some long-term strength criteria of rocks were established to study the creep behaviors of rocks, such as Mises-Schleicher \&Drucker-Prager unified(MSDPu) criterion, and so on. However, these long-term strength criteria were established using phenomenological approaches, which can produce the macroscopically observed creep curves of rocks by fitting with experimental data, and the inherent physical mechanisms related to time-dependent behaviors are not accommodated in these models, so the key mechanistic parameters remain physically unclear [7]. To authors' knowledge, three-dimensional long-term strength criterion of rocks, in which the effects of the intermediate principal stress are considered, is not proposed by using micromechanical methods. In fact, rock is a kind of discontinuity medium containing many microcracks and microdefects, the presence of such microcracks strongly influences the macroscopic mechanical behavior of rocks by serving as stress concentrators and leading to microcracking [8-12].

To overcome the disadvantages encountered in phenomenological models, it is necessary to study the effects of initiation and propagation of microcracks and microdefects on the creep failure of rocks. In this paper, micromechanical methods are used to investigate the lone-term strength of rocks. Moreover, a novel micromechanics-based three-dimensional nonlinear long-term strength criterion is established to study the effects of time and the intermediate principal stress on the creep failure of rocks. By comparison with experimental data, it is found that the novel micromechanics-based threedimensional long-term strength criterion is in good agreement with the experimental data.

\section{THE ANALYTICAL MODEL}

I $\mathrm{t}$ is generally accepted that the creep deformation and fracturing process that evolve in rocks are closely related to the intrinsic property and stress condition of rocks, such as fracture toughness, internal frictional angle, the dip and orientation angle of microcracks, Poisson's ratio, and so on. In this paper, it is assumed that the creep failure of rocks is due to the presence of penny-shaped microcracks and there is abundant evidence for the existence of microcracks in rocks [13-14]. Therefore, this model is physically plausible and the following assumptions are made: (i) penny-shaped microcracks are assumed to be randomly distributed in Burgers viscoelastic rock matrix; (ii) the interaction between penny-shaped microcracks is neglected before the coalescence of microcracks.

\section{Stress intensity factor of penny-shaped microcracks embedded in Burgers viscoelastic rock matrix}

It is assumed that the tensile stress is negative, and the compressive stress is positive. Consider a single penny-shaped creep microcrack in Burgers viscoelastic rock matrix uniformly loaded at far field. Establish a global coordinate system $\left(O-x_{1} x_{2} x_{3}.\right)$ and its corresponding local coordinate system $\left(O-x_{1}^{\prime} x_{2}^{\prime} x_{3}^{\prime}\right)$, as shown in Fig. 1. In a global coordinate system $\left(O-x_{1} x_{2} x_{3}\right)$, the direction of the maximum principal stress is parallel to the $x_{1}$-axis, the direction of the intermediate principal stress is parallel to the $x_{2}$-axis, the direction of the minimum principal stress is parallel to the $x_{3}$ axis. In the local coordinate system $\left(O-x_{1}^{\prime} x_{2}^{\prime} x_{3}^{\prime}\right)$, the direction of the $x_{2}^{\prime}$-axis is parallel to the normal direction of penny-shaped creep microcrack. The angle between the $x_{2}^{\prime}$-axis and the $x_{2}$-axis is the dip angle of penny-shaped creep microcrack $\theta$. The angle between the $x_{3}^{\prime}$-axis and the $x_{3}$-axis is the orientation angle of penny-shaped creep microcrack $\varphi$.

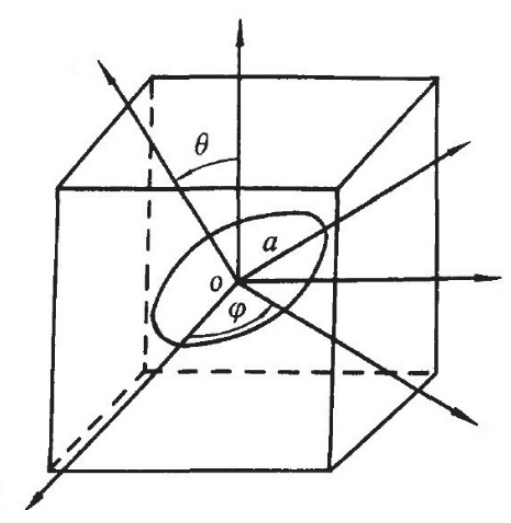

Figure 1: Mechanical model for penny-shaped microcrack embedded by Burgers viscoelastic rock matrix. 
The stresses in the local coordinate system are given by Yu and Feng [15],

$$
\sigma_{i j}^{\prime}=g_{i k}^{\prime} g_{j l}^{\prime} \sigma_{k l}
$$

where,

$$
g_{i j}^{\prime}=\left[\begin{array}{ccc}
\cos \theta \cos \varphi & \sin \theta & -\cos \theta \sin \varphi \\
-\sin \theta \cos \varphi & \cos \theta & \sin \theta \sin \varphi \\
\sin \varphi & 0 & \cos \varphi
\end{array}\right]
$$

Then, $\sigma_{22}^{\prime}, \sigma_{21}^{\prime}$ and $\sigma_{23}^{\prime}$ can be respectively expressed as follows:

$$
\left\{\begin{array}{l}
\sigma_{22}^{\prime}=\sigma_{1} \sin ^{2} \theta \cos ^{2} \varphi+\sigma_{2} \cos ^{2} \theta+\sigma_{3} \sin ^{2} \theta \sin ^{2} \varphi \\
\sigma_{21}^{\prime}=\sigma_{2} \sin \theta \cos \theta-\sigma_{1} \sin \theta \cos \theta \cos ^{2} \varphi-\sigma_{3} \sin \theta \cos \theta \sin ^{2} \varphi \\
\sigma_{23}^{\prime}=\sigma_{3} \sin \theta \sin \varphi \cos \varphi-\sigma_{1} \sin \theta \sin \varphi \cos \varphi
\end{array}\right.
$$

Yu and Feng [15] and Tada [16] defined the stress intensity factors at tips of penny-shaped microcracks embedded in isotropic and elastic rock matrix as

$$
K_{I I}=\frac{4\left[\sqrt{\left(\sigma_{21}^{\prime}\right)^{2}+\left(\sigma_{23}^{\prime}\right)^{2}}-\mu\left(\sigma_{22}^{\prime}\right)\right]}{2-v} \sqrt{\frac{a}{\pi}}
$$

where $\mu$ is the frictional coefficient on the crack surfaces, $v$ is Poisson's ratio, $K_{\mathrm{II}}$ is the mode II stress intensity factor.

\section{The Burgers creep model}

In this paper, it is assumed that microcracks are embedded in Burgers viscoelastic rock matrix with the characteristic of instantaneous elastic deformation, primary creep and steady-rate creep.

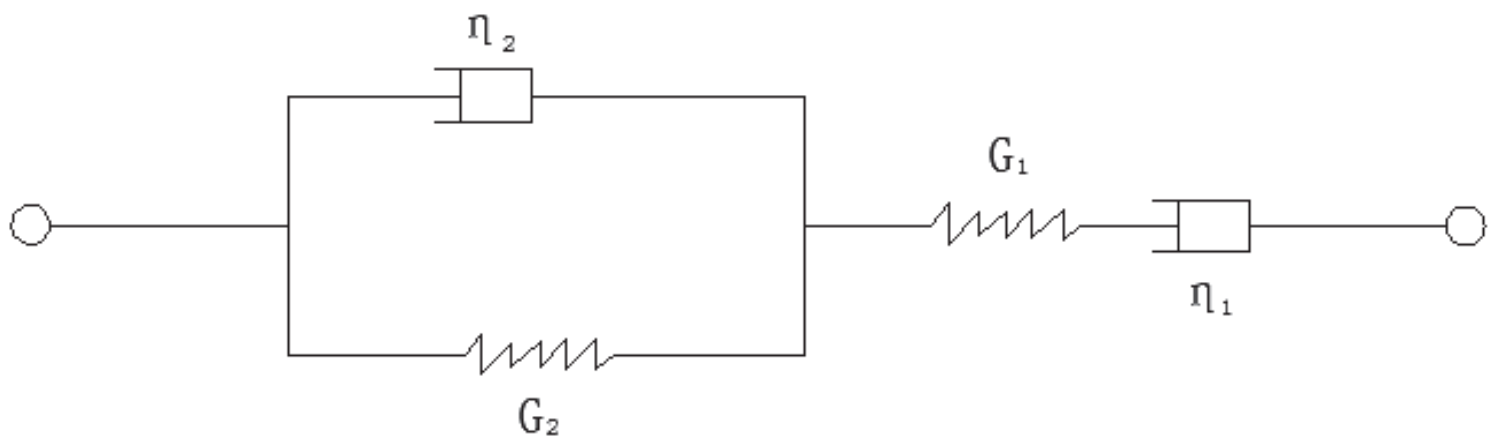

Figure 2: The diagram of Burgers model.

As shown in Fig. 2, Burgers model can be expressed as follows

$$
e_{i j}^{\prime \prime}+\frac{G_{2}}{\eta_{2}} e_{i j}^{\prime}=\frac{1}{2 G_{1}} S_{i j}+\left(\frac{1}{2 \eta_{2}}+\frac{1}{2 \eta_{1}}+\frac{G_{2}}{2 G_{1} \eta_{2}}\right) S_{i j}^{\prime}+\frac{G_{2}}{2 \eta_{1} \eta_{2}} S_{i j}^{\prime \prime}
$$


where $G_{1}$ is Maxwell shear modulus, $G_{2}$ is Kelvin shear modulus, $\eta_{1}$ is Maxwell viscosity, and $\eta_{2}$ is Kelvin viscosity, $S_{i j}=\sigma_{i j}-\frac{\delta_{i j}}{3}\left(\sigma_{11}+\sigma_{22}+\sigma_{33}\right), e_{i j}=\varepsilon_{i j}-\frac{\delta_{i j}}{3}\left(\varepsilon_{11}+\varepsilon_{22}+\varepsilon_{33}\right), \delta_{i j}=\left\{\begin{array}{ll}1 & i=j \\ 0 & i \neq j\end{array}, \sigma_{i j}\right.$ is stress tensor, $\varepsilon_{i j}$ is strain tensor. The Maxwell shear modulus is equal to elasticity shear modulus, $e_{i j}^{\prime \prime}=\frac{d^{2} e_{i j}}{d t^{2}}, e_{i j}^{\prime}=\frac{d e_{i j}}{d t}, S_{i j}^{\prime \prime}=\frac{d^{2} S_{i j}}{d t^{2}}, S_{i j}^{\prime}=\frac{d S_{i j}}{d t}$.

Eq.(5) can be rewritten as

$$
e_{i j}=S_{i j}\left[\frac{1}{2 G_{1}}+\frac{t}{2 \eta_{1}}+\frac{1}{2 G_{2}}\left(1-e^{\frac{G_{2}}{\eta_{2}} t}\right)\right]
$$

where $t$ is the creep time.

From Eq.(6) and works by Yi and Zhu [17], the time factor of the Burgers model under a given load is obtained as

$$
\left\{\begin{array}{l}
f_{i \sigma}(t)=H(t) \\
f_{i u}(t)=1+\frac{G_{1}}{\eta_{1}} t+\frac{G_{1}}{G_{2}}\left[1-\exp \left(-\frac{G_{2}}{\eta_{2}} t\right)\right]
\end{array}\right.
$$

where $f_{i n}(t)$ is the time factor for displacement, $f_{i \sigma}(t)$ is the time factor for stress, $H(t)=\left\{\begin{array}{l}1, t \geq 0 \\ 0, t<0\end{array}\right.$ is Heaviside function.

According to works by Zhou [18], energy release rate at tips of the mixed mode I- II-III microcracks in Burgers viscoelastic rock matrix can be written as

$$
G(t)=G_{I}(t)+G_{I I}(t)+G_{I I I}(t)=\frac{1-v^{2}}{E}\left(K_{I}^{2}+K_{I I}^{2}+\frac{1}{1-v} K_{I I I}^{2}\right) f_{i u}(t)
$$

where

$$
f_{i u}(t)=1+\frac{G_{1}}{\eta_{1}} t+\frac{G_{1}}{G_{2}}\left[1-\exp \left(-\frac{G_{2}}{\eta_{2}} t\right)\right]
$$

In Eq. (8), $G(t)$ can be rewritten as

$$
G(t)=f_{i u}(t) G
$$

where $G$ is energy release rate at tips of the mixed mode I-II-III microcracks in elastic rock matrix.

As for the creep fracture, the stress and displacement fields at tips of microcracks can be obtained as follows:

$$
\left\{\begin{array}{l}
\sigma_{i j}^{(m)}(t)=\sigma_{i j}^{(m)} \frac{K_{m}(t)}{K_{m}} \\
u_{i}^{(m)}(t)=u_{i}^{(m)} \frac{K_{m}(t)}{K_{m}}
\end{array}\right.
$$


where $m=\mathrm{I}$, II and III, which are, respectively, denoted by mode I, II and III microcracks, $\sigma_{i j}^{(m)}$ and $u_{i}^{(m)}$ are, respectively, the stress and displacement fields at tips of microcracks in elastic rock matrix, $\sigma_{i j}^{(m)}(t)$ and $u_{i}^{(m)}(t)$ are, respectively, the stress and displacement fields at tips of microcracks in Burgers viscoelastic rock matrix, $K_{m}(t)$ and $K_{m}$ are, respectively, stress intensity factor at tips of microcracks in Burgers viscoelastic and elastic rock matrix.

According to the definition of stress intensity factor, stress intensity factor at tips of microcracks can be denoted by

$$
\left\{\begin{array}{l}
K_{m}=\lim _{x \rightarrow 0}\left[\left.\sigma_{i j}^{(m)}\right|_{y=0} \sqrt{2 \pi x}\right] \\
K_{m}(t)=\lim _{x \rightarrow 0}\left\{\left.\sigma_{i j}^{(m)}(t)\right|_{y=0} \sqrt{2 \pi x}\right\}
\end{array}\right.
$$

Based on the definition of energy release rate, energy release rate at tips of microcracks can be defined by

$$
G(t)=\lim _{\delta a \rightarrow 0} \frac{1}{\delta a} \int_{0}^{\delta a}\left[\sigma_{y y}(x, 0) u_{y}(x-\delta a, 0)+\sigma_{y x}(x, 0) u_{x}(x-\delta a, 0)+\sigma_{y z}(x, 0) u_{z}(x-\delta a, 0)\right] d x
$$

where $a$ is the growth length of microcracks.

Substituting Eq. (10) into Eq. (12) yields

$$
\begin{aligned}
G(t) & =\lim _{\delta a \rightarrow 0} \frac{1}{\delta a} \int_{0}^{\delta a}\left[\sigma_{i j}^{(m)}(t) u_{i}^{(m)}(t)\right] d x \\
= & \lim _{\delta a \rightarrow 0} \frac{1}{\delta a} \int_{0}^{\delta a}\left\{\sigma_{i j}^{(m)} \frac{K_{m}(t)}{K_{m}}\right\}\left\{u_{i}^{(m)} \frac{K_{m}(t)}{K_{m}}\right\} d x \\
= & \lim _{\delta a \rightarrow 0} \frac{1}{\delta a} \int_{0}^{\delta a}\left[\sigma_{i j}^{(m)} u_{i}^{(m)}\right] d x \\
= & \frac{\left[K_{m}(t)\right]^{2}}{\left(K_{m}\right)^{2}} G
\end{aligned}
$$

From Eq. (13) and Eq. (9), the stress intensity factors of creep cracks can be written as

$$
K_{m}(t)=K_{m} \sqrt{\frac{G(t)}{G}}=K_{m} \sqrt{f_{i u}(t)}
$$

For three-dimensional penny-shaped microcracks, frictional sliding is caused by the effective shear stress. As the effective shear force is greater than the frictional resistance along the slip surface, frictional slip would lead to the tensile stress at the two tips of the slip surface, which form the wing cracks, as shown in Fig. 3.

Substituting Eq. (4) into Eq. (14) yields:

$$
K_{I I}=\frac{4 \sqrt{f_{i u}(t)}\left[\sqrt{\left(\sigma_{21}^{\prime}\right)^{2}+\left(\sigma_{23}^{\prime}\right)^{2}}-\mu\left(\sigma_{22}^{\prime}\right)\right]}{2-v} \sqrt{\frac{a}{\pi}}
$$

where $\mu$ is the frictional coefficient on the crack surfaces, $v$ is Poisson's ratio, $K_{I I}$ is the mode II stress intensity factor, $f(t)$ denotes the time factor.

According to works by Tada [16], the condition of unstable growth of the mode II microcracks can be written as

$$
K_{I I}\left(t_{0}\right)=\kappa K_{I C}
$$


where

$$
\left\{\begin{array}{l}
\sigma_{22}^{\prime}=\sigma_{1} \sin ^{2} \theta \cos ^{2} \varphi+\sigma_{2} \cos ^{2} \theta+\sigma_{3} \sin ^{2} \theta \sin ^{2} \varphi \\
\sigma_{21}^{\prime}=\sigma_{2} \sin \theta \cos \theta-\sigma_{1} \sin \theta \cos \theta \cos ^{2} \varphi-\sigma_{3} \sin \theta \cos \theta \sin ^{2} \varphi \\
\sigma_{23}^{\prime}=\sigma_{3} \sin \theta \sin \varphi \cos \varphi-\sigma_{1} \sin \theta \sin \varphi \cos \varphi
\end{array}\right.
$$

$\kappa$ can be obtained from experimental results, or approximation suggested in the literature on the kinked crack, such as $\kappa=\sqrt{3} / 2$ in the maximum-stress criterion [19], $t_{0}$ is the time of creep failure of microcracks, $K_{I C}$ is toughness of rocks, which can be obtained by induced tensile strength and crack length, namely

$$
K_{I C}=2 \sigma_{t} \sqrt{\frac{a}{\pi}}
$$

where $\sigma_{t}$ is short-term uniaxial tensile strength of rocks.

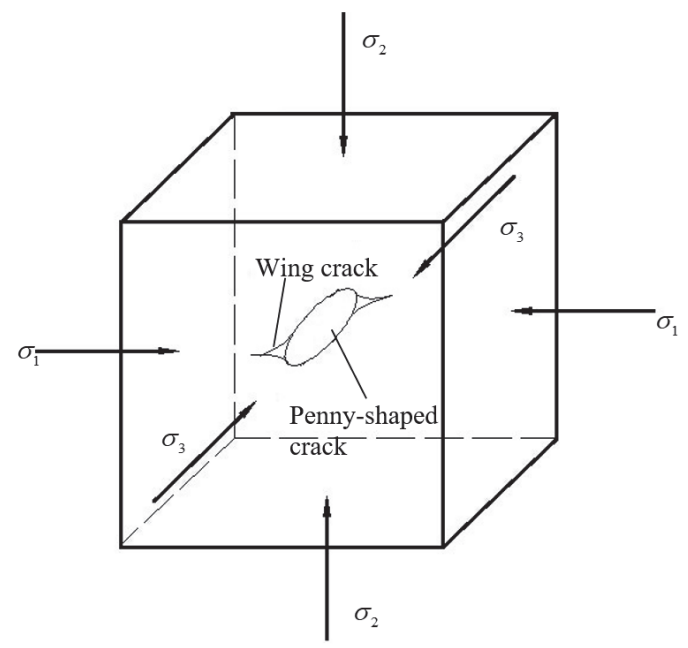

Figure 3: Propagation of wing cracks from the tip of penny-shaped microcrack.

\section{THE ORIENTATION ANGLE OF MICRO-FAILURE IN ROCKS}

I $t$ is generally accepted that the creep failure of rocks is induced by the fragment of large amounts of internal microcracks. However, it is very difficult to quantitatively analyze the number of microcracks. Therefore, microfailure orientation angle $\alpha$ is introduced to define the number of propagating penny-shaped creepmicrocracks, as shown in Fig. 4. The fan-shaped area of wing crack distribution zone shown in Fig. 4 can be obtained from Eqs(15)-(16). The included angle of the fan section is denoted as the micro-failure orientation angle $\alpha$. Substituting Eq.(15) into Eq.(16) yields:

$$
\begin{aligned}
& \left(\sigma_{1}-\sigma_{3}\right)^{2}\left(\mu^{2}-1\right) \sin ^{4} \theta \cos ^{4} \varphi+\left(\sigma_{1}-\sigma_{3}\right) \\
& \sin ^{2} \theta\left[2 c \mu+2\left(\sigma_{2}-\sigma_{3}\right) \cos ^{2} \theta+2 \mu^{2}\left(\sigma_{2} \cos ^{2} \theta+\sigma_{3} \sin ^{2} \theta\right)-\left(\sigma_{1}-\sigma_{3}\right)\right] \cos ^{2} \varphi \\
& +\left\{-\left(\sigma_{2}-\sigma_{3}\right)^{2} \sin ^{2} \theta \cos ^{2} \theta+\left[c+\mu\left(\sigma_{2} \cos ^{2} \theta+\sigma_{3} \sin ^{2} \theta\right)\right]^{2}\right\} \leq 0
\end{aligned}
$$


where $\mathrm{c}=\frac{\kappa \sigma_{t}(2-v)}{2 \sqrt{f_{\text {iu }}(t)}}, \sigma_{1}$ is the maximum principal stress, $\sigma_{2}$ is the intermediate principal stress, $\sigma_{3}$ is the minimum principal stress, the compressive stresses are defined to be positive in this paper.

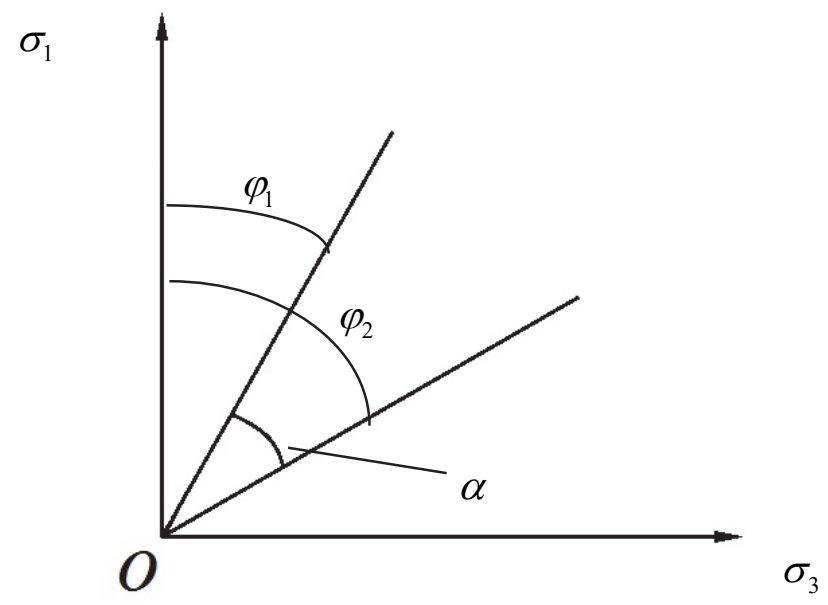

Figure 4: Wing crack distribution zone

Eq.(18) can be rewritten as :

$$
C_{1} \cos ^{4} \varphi+C_{2} \cos ^{2} \varphi+C_{3} \leq 0
$$

where

$$
\left\{\begin{array}{l}
C_{1}=\left(\sigma_{1}-\sigma_{3}\right)^{2}\left(\mu^{2}+1\right) \sin ^{4} \theta \\
C_{2}=\left(\sigma_{1}-\sigma_{3}\right) \sin ^{2} \theta\left[2 c \mu+2 \cos ^{2} \theta\left(\mu^{2}+1\right) \sigma_{2}+2\left(\mu^{2} \sin ^{2} \theta-\cos ^{2} \theta\right) \sigma_{3}-\left(\sigma_{1}-\sigma_{3}\right)\right] \\
C_{3}=-\left(\sigma_{2}-\sigma_{3}\right)^{2} \sin ^{2} \theta \cos ^{2} \theta+\left[c+\mu\left(\sigma_{2} \cos ^{2} \theta+\sigma_{3} \sin ^{2} \theta\right)\right]^{2}
\end{array}\right.
$$

From Eq. (19), the cosine of $\varphi$ can be written as

$$
\cos ^{2} \varphi_{1} \leq \cos ^{2} \varphi \leq \cos ^{2} \varphi_{2}
$$

where

$$
\left\{\begin{array}{l}
\cos ^{2} \varphi_{1}=\frac{-C_{2}+\sqrt{C_{2}^{2}-4 C_{1} C_{3}}}{2 C_{1}} \\
\cos ^{2} \varphi_{2}=\frac{-C_{2}-\sqrt{C_{2}^{2}-4 C_{1} C_{3}}}{2 C_{1}}
\end{array}\right.
$$

From Eq.(20), supposing $\alpha=\varphi_{2}-\varphi_{1}$, the following equation can be written

$$
\cos \alpha=\cos \left(\varphi_{2}-\varphi_{1}\right)=\cos \varphi_{2} \cos \varphi_{1}+\sin \varphi_{2} \sin \varphi_{1}
$$




\section{CREEP FAILURE CHARACTERISTIC PARAMETERS OF ROCKS}

$\mathrm{T}$

he creep failure characteristic parameter of rocks should be constant when rocks entirely break. Damage mechanics reveals that the nucleation and initiation of microcracks does not imply creep failure of rock-like materials [20-22]. Many experiments show that the maximum principal stress should be further increased to assure that the wing crack continually propagates, while the minimum principal stress can significantly restrain wing crack to grow [23]. Therefore, the initiation of wing cracks cannot indicate creep failure of rocks. As a result, nucleation and initiation of internal microcracks cannot be chosen as the creep failure characteristic parameters.

The larger the minimum principal stress, the smaller the micro-failure orientation angle $\alpha$. The micro-failure orientation angle $\alpha$ does not keep constant, $\tan \alpha, \sin \alpha$ and $\cos \alpha$ do not also keep constant. Therefore, the micro-failure orientation angle $\alpha, \tan \alpha, \sin \alpha$ and $\cos \alpha$ cannot be considered as the creep failure characteristic parameters.

Microcracks randomly distribute in Burgers viscoelastic rock matrix, and the orientation angle of each microcrack randomly distributes. Therefore, the micro-failure orientation angle $\alpha$ can be adopted to investigate the micro-failure density. An increase in the minimum principal stress leads to a decrease in the micro-failure density. The internal microfailure density does not keep constant. Therefore, the micro-failure density cannot also be chosen as the creep failure characteristic parameters.

Reference [24] suggested that the creep failure of rocks occurs when the volumetric strain due to the internal micro-failure density reaches a critical value. Therefore, the creep failure characteristic parameters of rocks should be relevant to the internal micro-failure density, which is related to the micro-failure orientation angle $\alpha$. Moreover, the creep failure characteristic parameters should satisfy the following three principles: firstly, the expression of the creep failure characteristic parameter should be in a simple mathematic one; secondly, the higher the minimum principal stress, the lower the micro-failure orientation angle; finally, the theoretical result should agree well with the experimental data.

Obviously, the expressions of the micro-failure orientation angle $\alpha, \tan \alpha$ and $\sin \alpha$ are so complicated that it cannot be chosen as the creep failure characteristic parameters. Compared with the expressions of $\alpha, \tan \alpha$ and $\sin \alpha$, the expression of $\cos \alpha$ is the simplest. The expression of $\sigma_{1}=\sigma_{c}$ is also the simplest Therefore, $\sigma_{1}=\sigma_{c}$ satisfies the first and second principles.

According to the second principle and Eq. (21), the cosine of the micro-failure orientation angle $\alpha$ can be expressed in following form:

$$
\cos \alpha=\sqrt{\frac{C_{3}}{C_{1}}}+\sqrt{1+\frac{C_{2}}{C_{1}}+\frac{C_{3}}{C_{1}}}
$$

where

$$
\left\{\begin{array}{l}
C_{1}=C_{11} \sigma^{2} \\
C_{2}=C_{21} \sigma^{2}+C_{22} \sigma \\
C_{3}=-\left(\sigma_{2}-\sigma_{3}\right)^{2} \sin ^{2} \theta \cos ^{2} \theta+\left[c+\mu\left(\sigma_{2} \cos ^{2} \theta+\sigma_{3} \sin ^{2} \theta\right)\right]^{2} \\
C_{11}=\left(\mu^{2}+1\right) \sin ^{4} \theta \\
C_{21}=-\sin ^{2} \theta \\
C_{22}=\sin ^{2} \theta\left[2 c \mu+2 \cos ^{2} \theta\left(\mu^{2}+1\right) \sigma_{2}+2\left(\mu^{2} \sin ^{2} \theta-\cos ^{2} \theta\right) \sigma_{3}\right] \\
\sigma=\sigma_{1}-\sigma_{3}
\end{array}\right.
$$


It is indicated from Eq.(22) that the cosine of the micro-failure orientation angle increases with an increase in the minimum principal stress $\sigma_{3}$, while the micro-failure orientation angle $\alpha$ decreases with increasing the minimum principal stress $\sigma_{3}$.

For an invariable intermediate principal stress $\sigma_{2}$ and an invariable minimum principal stress $\sigma_{3}$, the relationship between $\cos \alpha$ and the maximum principal stress can be defined. Differentiating Eq. (22) with respect to $\sigma_{1}$ yields:

$$
\left|\frac{\partial \cos \alpha}{\partial \sigma_{1}}\right|=\frac{1}{\sqrt{C_{11}} \sigma^{2}}\left(\sqrt{C_{3}}+\frac{C_{22} \sigma+2 C_{3}}{2 \sqrt{\left(C_{11}+C_{21}\right) \sigma^{2}+C_{22} \sigma+C_{3}}}\right)
$$

where $\left|\frac{\partial \cos \alpha}{\partial \sigma_{1}}\right|$ is defined as the rate of change of $\cos \alpha$ to the maximum principal stress.

From Eq. (22), the maximum principal stress can be expressed as

$$
\sigma=\sigma_{1}-\sigma_{3}=-\frac{2 \cos \alpha \sqrt{C_{11} C_{3}}+C_{22}}{C_{21}+C_{11} \sin ^{2} \alpha}
$$

Substituting Eq. (24) into Eq. (23) yields

$$
\begin{aligned}
& \left|\frac{\partial \cos \alpha}{\partial \sigma_{1}}\right|=\frac{\left(C_{21}+C_{11} \sin ^{2} \alpha\right)^{2}}{\sqrt{C_{11}}\left(C_{22}+2 \sqrt{C_{11} C_{3}} \cos \alpha\right)^{2}} \\
& \left\{\sqrt{C_{3}}+\frac{-C_{22}^{2}-2 C_{22} \sqrt{C_{11} C_{3}} \cos \alpha+2 C_{3}\left(C_{21}+C_{11} \sin ^{2} \alpha\right)}{2 \sqrt{C_{3}+\left(C_{11}+C_{21}\right)\left(C_{22}+2 \sqrt{C_{11} C_{3}} \cos \alpha\right)^{2}-C_{22}\left(C_{22}+2 \sqrt{C_{11} C_{3}} \cos \alpha\right)\left(C_{21}+C_{11} \sin ^{2} \alpha\right)}}\right\}
\end{aligned}
$$

If the short-term uniaxial compressive strength of rocks is known, three-dimensional long-term strength criterion of rocks can be expressed by short-term uniaxial compressive strength of rocks. Therefore, for the short-term uniaxial compression condition $\sigma_{1}=\sigma_{c}, \sigma_{2}=0, \sigma_{3}=0$, we can obtain $\left|\partial \cos \alpha / \partial \sigma_{1}\right|$ at $t=0$ as,

$$
\left|\frac{\partial \cos \alpha}{\partial \sigma_{1}}\right|=\frac{c_{0}}{\sigma_{c}^{2} \sqrt{\mu^{2}+1}}\left[\csc ^{2} \theta+\frac{\mu \sigma_{c}+c_{0} \csc ^{2} \theta}{\sqrt{\left(c_{0}+\mu \sigma_{c} \sin ^{2} \theta\right)^{2}-\sigma_{c}^{2} \sin ^{2} \theta \cos ^{2} \theta}}\right]
$$

where $c_{0}=\frac{\kappa \sigma_{t}(2-v)}{2 \sqrt{f_{i u}(0)}}, \sigma_{c}$ is the short-term uniaxial compressive strength of rocks, $f_{i u}(0)$ is the time factor when $t=0$. Substituting Eq. (23) into Eq. (26) yields

$$
\begin{aligned}
& \frac{1}{\sqrt{C_{11}} \sigma^{2}}\left(\sqrt{C_{3}}+\frac{C_{22} \sigma+2 C_{3}}{2 \sqrt{\left(C_{11}+C_{21}\right) \sigma^{2}+C_{22} \sigma+C_{3}}}\right)= \\
& \frac{c_{0}}{\sigma_{c}^{2} \sqrt{\mu^{2}+1}}\left[\csc ^{2} \theta+\frac{\mu \sigma_{c}+c_{0} \csc ^{2} \theta}{\sqrt{\left(c_{0}+\mu \sigma_{c} \sin ^{2} \theta\right)^{2}-\sigma_{c}^{2} \sin ^{2} \theta \cos ^{2} \theta}}\right]
\end{aligned}
$$


From Eq. (27), three-dimensional long-term strength criterion expressed by the short-term uniaxial compressive strength of rocks can be denoted by

$$
A_{1}\left(\sigma_{1}-\sigma_{3}\right)^{4}+A_{2}\left(\sigma_{1}-\sigma_{3}\right)^{3}+A_{3}\left(\sigma_{1}-\sigma_{3}\right)^{2}+A_{4}\left(\sigma_{1}-\sigma_{3}\right)+A_{5}=0
$$

where

$$
\left\{\begin{array}{l}
A_{1}=4 C_{11} C_{4}^{2}\left(C_{11}+C_{21}\right) \\
A_{2}=4 C_{11} C_{22} C_{4}^{2} \\
A_{3}=4\left[C_{11} C_{3} C_{4}^{2}-2\left(C_{11}+C_{21}\right) C_{4} \sqrt{C_{11} C_{3}}\right] \\
A_{4}=-2 C_{22} C_{4} \sqrt{C_{11} C_{3}} \\
A_{5}=4\left[C_{3}\left(C_{11}+C_{21}\right)-2 C_{3} C_{4} \sqrt{C_{11} C_{3}}\right]-C_{22}^{2} \\
C_{11}=\left(\mu^{2}+1\right) \sin ^{4} \theta \\
C_{21}=-\sin ^{2} \theta \\
C_{22}=\sin ^{2} \theta\left[2 c \mu+2 \cos ^{2} \theta\left(\mu^{2}+1\right) \sigma_{2}+2\left(\mu^{2} \sin ^{2} \theta-\cos ^{2} \theta\right) \sigma_{3}\right] \\
C_{3}=-\left(\sigma_{2}-\sigma_{3}\right)^{2} \sin ^{2} \theta \cos ^{2} \theta+\left[c+\mu\left(\sigma_{2} \cos ^{2} \theta+\sigma_{3} \sin ^{2} \theta\right)\right]^{2} \\
C_{4}=\frac{c_{0}}{\sigma_{c}^{2} \sqrt{\mu^{2}+1}}\left[\csc ^{2} \theta+\frac{\sqrt{\left(c_{0}+\mu \sigma_{c} \sin ^{2} \theta\right)^{2}-\sigma_{c}^{2} \sin ^{2} \theta \cos ^{2} \theta}}{\sqrt{c^{2} \theta}}\right]
\end{array}\right.
$$

It is observed from Eq. (28) that $\left(\sigma_{1}-\sigma_{3}\right)$ is related to the friction coefficient $\mu$, the coefficient $\kappa$ of mixed-mode fracture criterion, the short-term uniaxial compressive strength $\sigma_{c}$, the short-term uniaxial tensile strength $\sigma_{t}$, the time factor $f_{i u}(0)$, the dip angle of penny-shaped microcracks $\theta$ and Poisson's ratio $v$.

If the long-term uniaxial compressive strength of rocks is known, three-dimensional long-term strength criterion of rocks can be expressed by long-term uniaxial compressive strength of rocks. Therefore, for the long-term uniaxial compressive condition $\sigma_{1}=\sigma_{c l}, \sigma_{2}=0, \sigma_{3}=0$, we can obtain the rate of change constant $\left|\partial \cos \alpha / \partial \sigma_{1}\right|\left|\partial \cos \alpha / \partial \sigma_{1}\right|$ at $t=t_{0}$ as,

$$
\left|\frac{\partial \cos \alpha}{\partial \sigma_{1}}\right|=\frac{c_{t_{0}}}{\sigma_{c l}^{2} \sqrt{\mu^{2}+1}}\left[\csc ^{2} \theta+\frac{\mu \sigma_{c l}+c_{t_{0}} \csc ^{2} \theta}{\sqrt{\left(c_{t_{0}}+\mu \sigma_{c l} \sin ^{2} \theta\right)^{2}-\sigma_{c l}^{2} \sin ^{2} \theta \cos ^{2} \theta}}\right]
$$

where $\quad c_{t_{0}}=\frac{\kappa \sigma_{t}(2-v)}{2 \sqrt{f_{i u}\left(t_{0}\right)}} \quad, \sigma_{c l}$ is the long-term uniaxial compressive strength of rocks, $f_{i u}\left(t_{0}\right)$ is the time factor when $t=t_{0}, t_{0}$ is the time of creep failure of rocks under uniaxial compressive loads.

Substituting Eq. (29) into Eq. (23) yields: 


$$
\begin{aligned}
& \frac{1}{\sqrt{C_{11}} \sigma^{2}}\left(\sqrt{C_{3}}+\frac{C_{22} \sigma+2 C_{3}}{2 \sqrt{\left(C_{11}+C_{21}\right) \sigma^{2}+C_{22} \sigma+C_{3}}}\right)= \\
& =\frac{c_{t_{0}}}{\sigma_{c l}^{2} \sqrt{\mu^{2}+1}}\left[\csc ^{2} \theta+\frac{\mu \sigma_{c l}+c_{t_{0}} \csc ^{2} \theta}{\sqrt{\left(c_{t_{0}}+\mu \sigma_{c l} \sin ^{2} \theta\right)^{2}-\sigma_{c l}^{2} \sin ^{2} \theta \cos ^{2} \theta}}\right]
\end{aligned}
$$

From Eq. (30), micromechanics-based three-dimensional long-term strength criterion of rocks expressed by long-term uniaxial compressive strength of rocks can written as

$$
A_{1}\left(\sigma_{1}-\sigma_{3}\right)^{4}+A_{2}\left(\sigma_{1}-\sigma_{3}\right)^{3}+A_{3}\left(\sigma_{1}-\sigma_{3}\right)^{2}+A_{4}\left(\sigma_{1}-\sigma_{3}\right)+A_{5}=0
$$

where

$$
\left\{\begin{array}{l}
A_{1}=4 C_{11} C_{4}^{2}\left(C_{11}+C_{21}\right) \\
A_{2}=4 C_{11} C_{22} C_{4}^{2} \\
A_{3}=4\left[C_{11} C_{3} C_{4}^{2}-2\left(C_{11}+C_{21}\right) C_{4} \sqrt{C_{11} C_{3}}\right] \\
A_{4}=-2 C_{22} C_{4} \sqrt{C_{11} C_{3}} \\
A_{5}=4\left[C_{3}\left(C_{11}+C_{21}\right)-2 C_{3} C_{4} \sqrt{C_{11} C_{3}}\right]-C_{22}^{2} \\
C_{11}=\left(\mu^{2}+1\right) \sin ^{4} \theta \\
C_{21}=-\sin ^{2} \theta \\
C_{22}=\sin ^{2} \theta\left[2 c \mu+2 \cos ^{2} \theta\left(\mu^{2}+1\right) \sigma_{2}+2\left(\mu^{2} \sin ^{2} \theta-\cos ^{2} \theta\right) \sigma_{3}\right] \\
C_{3}=\left[c+\mu\left(\sigma_{2} \cos ^{2} \theta+\sigma_{3} \sin ^{2} \theta\right)\right]^{2}-\left(\sigma_{2}-\sigma_{3}\right)^{2} \sin ^{2} \theta \cos ^{2} \theta \\
C_{4}=\frac{c_{t_{0}}}{\sigma_{c l}^{2} \sqrt{\mu^{2}+1}}\left[\csc ^{2} \theta+\frac{\mu \sigma_{c l}+c_{t_{0}} \csc ^{2} \theta}{\sqrt{\left(c_{t_{0}}+\mu \sigma_{c l} \sin ^{2} \theta\right)^{2}-\sigma_{c l}^{2} \sin ^{2} \theta \cos ^{2} \theta}}\right]
\end{array}\right.
$$

It is observed from Eq. (31) that $\left(\sigma_{1}-\sigma_{3}\right)$ is related to the friction coefficient $\mu$, the coefficient $\kappa$ of mixed-mode fracture criterion, the long-term uniaxial compressive strength $\sigma_{c l}$, the short-term uniaxial tensile strength $\sigma_{t}$, the time factor $f_{i u}\left(t_{0}\right)$, the dip angle of penny-shaped microcracks $\theta$ and Poisson's ratio $v$.

Assumed that

$$
\left(C_{11}+C_{21}\right)=0, C_{22}=s \sigma_{c l}+m \sigma_{2}-n \sigma_{3}, C_{3}=\left(s \sigma_{c l}+m \sigma_{2}-n \sigma_{3}\right)^{2}
$$

Eq.(31) can be simplified to:

$$
\left(\sigma_{1}-\sigma_{3}\right)^{3}+\left(s \sigma_{c l}+m \sigma_{2}-n \sigma_{3}\right)\left(\sigma_{1}-\sigma_{3}-s \sigma_{c l}\right)^{2}-s \sigma_{c l}\left(s \sigma_{c l}+m \sigma_{2}-n \sigma_{3}\right)^{2}=0
$$

where $s, n$ and $m$ are the strength parameters which are determined by experiments. 
When Eq.(32) is expressed by the short-term uniaxial compressive strength $\sigma_{c}$, Eq.(32) can be rewritten as

$$
\begin{aligned}
& \left(\sigma_{1}-\sigma_{3}\right)^{3}+\left(\frac{s \sigma_{c} \sqrt{f_{\text {iu }}(0)}}{\sqrt{f_{\text {iu }}\left(t_{0}\right)}}+m \sigma_{2}-n \sigma_{3}\right) \\
& \left(\sigma_{1}-\sigma_{3}-\frac{s \sigma_{c} \sqrt{f_{\text {iu }}(0)}}{\sqrt{f_{\text {iu }}\left(t_{0}\right)}}\right)^{2}-\frac{s \sigma_{c} \sqrt{f_{\text {iu }}(0)}}{\sqrt{f_{\text {iu }}\left(t_{0}\right)}}\left(\frac{s \sigma_{c} \sqrt{f_{\text {iu }}(0)}}{\sqrt{f_{\text {iu }}\left(t_{0}\right)}}+m \sigma_{2}-n \sigma_{3}\right)^{2}=0
\end{aligned}
$$

where $\sigma_{c}$ is the short-term uniaxial compressive strength.

\section{COMPARISON WITH THE EXPERIMENTAL RESULTS}

$\mathrm{T}$

he Lode stress angle is defined as follows:

$$
\phi_{\sigma}=\arctan \left[\frac{2 \sigma_{3}-\left(\sigma_{1}+\sigma_{2}\right)}{\sqrt{3}\left(\sigma_{1}+\sigma_{2}\right)}\right] \quad\left(-30^{0} \leq \phi_{\sigma} \leq 30^{0}\right)
$$

The stress tensor $\sigma_{i j}$ expressed by the first invariant $I_{1}$ of stress tensor and the second invariant of deviatoric stress tensor $J_{2}$ can be written as follows:

$$
\left[\begin{array}{l}
\sigma_{1} \\
\sigma_{2} \\
\sigma_{3}
\end{array}\right]=\frac{2}{\sqrt{3}} \sqrt{J_{2}}\left[\begin{array}{l}
\sin \left(\phi_{\sigma}+\frac{2}{3} \pi\right) \\
\sin \left(\phi_{\sigma}\right) \\
\sin \left(\phi_{\sigma}-\frac{2}{3} \pi\right)
\end{array}\right]+\left[\begin{array}{l}
I_{1} / 3 \\
I_{1} / 3 \\
I_{1} / 3
\end{array}\right]
$$

Micromechanics-based three-dimensional long-term strength criterion (32) can be expressed by the first invariant $I_{1}$ of stress tensor and the second invariant of deviatoric stress tensor $J_{2}$, the following expression can be obtained

$$
F=f_{1}^{\prime} q^{3}+f_{2}^{\prime} p q^{2}+f_{3}^{\prime} q^{2}+f_{4}^{\prime} p q+f_{5}^{\prime} p^{2}+f_{6}^{\prime} q+f_{7}^{\prime} p=0
$$

where

$$
\left\{\begin{array}{l}
f_{1}^{\prime}=\frac{4}{3} \cos ^{2} \phi_{\sigma}\left[3(2+n) \cos \phi_{\sigma}+\sqrt{3}(2 m+n) \sin \phi_{\sigma}\right] \\
f_{2}^{\prime}=4(m-n) \cos ^{2} \phi_{\sigma} \\
f_{3}^{\prime}=\frac{1}{3} s \sigma_{c l}\left\{-2\left[-3+m^{2}+(3+m) n+n^{2}\right]+\left[6+2 m^{2}+2 m n-n(6+n)\right] \cos 2 \phi_{\sigma}-\sqrt{3}(2+n)(2 m+n) \sin 2 \phi_{\sigma}\right\} \\
f_{4}^{\prime}=-\frac{2}{3}(m-n) s \sigma_{c l}\left[3(2+n) \cos \phi_{\sigma}+\sqrt{3}(2 m+n) \sin \phi_{\sigma}\right] \\
f_{5}^{\prime}=-(m-n)^{2} s \sigma_{c l} \\
f_{6}^{\prime}=-\frac{1}{3} s^{2} \sigma_{c l}^{2}\left[3(4+n) \cos \phi_{\sigma}+\sqrt{3}(2 m+n) \sin \phi_{\sigma}\right] \\
f_{7}^{\prime}=(-m+n) s^{2} \sigma_{c l}^{2}
\end{array}\right.
$$




$$
p=I_{1} / 3, q=\sqrt{J_{2}}
$$

Similarly, Micromechanics-based three-dimensional long-term strength criterion (33) can be rewritten in another form:

$$
F=f_{1} q^{3}+f_{2} p q^{2}+f_{3} q^{2}+f_{4} p q+f_{5} p^{2}+f_{6} q+f_{7} p=0
$$

where

$$
\left\{\begin{array}{l}
f_{1}=\frac{4}{3} \cos ^{2} \phi_{\sigma}\left[3(2+n) \cos \phi_{\sigma}+\sqrt{3}(2 m+n) \sin \phi_{\sigma}\right] \\
f_{2}=4(m-n) \cos ^{2} \phi_{\sigma} \\
f_{3}=\frac{1}{3} s \sqrt{\frac{f_{i u}(0)}{f_{i u}\left(t_{0}\right)}} \sigma_{c}\left\{-2\left[-3+m^{2}+(3+m) n+n^{2}\right]+\left[6+2 m^{2}+2 m n-n(6+n)\right] \cos 2 \phi_{\sigma}-\sqrt{3}(2+n)(2 m+n) \sin 2 \phi_{\sigma}\right\} \\
f_{4}=-\frac{2}{3}(m-n) s \sqrt{\frac{f_{i u}(0)}{f_{i u}\left(t_{0}\right)}} \sigma_{c}\left[3(2+n) \cos \phi_{\sigma}+\sqrt{3}(2 m+n) \sin \phi_{\sigma}\right] \\
f_{5}=-(m-n)^{2} s \sqrt{\frac{f_{\text {iu }}(0)}{f_{i u}\left(t_{0}\right)}} \sigma_{c} \\
f_{6}=-\frac{1}{3} s^{2} \frac{f_{\text {iu }}(0)}{f_{\text {iu }}\left(t_{0}\right)} \sigma_{c}^{2}\left[3(4+n) \cos \phi_{\sigma}+\sqrt{3}(2 m+n) \sin \phi_{\sigma}\right] \\
f_{7}=(-m+n) s^{2} \frac{f_{i u}(0)}{f_{i u}\left(t_{0}\right)} \sigma_{c}^{2}
\end{array}\right.
$$

\section{COMPARISON WITH THE EXPERIMENTAL DATA OF COAL}

S

eries of triaxial compressive experimental data were obtained from creep tests on various rocks by Refs [25-27]. The long-term uniaxial compressive strength of rocks and the fitting strength parameters are listed in Tab. 1. Tabs. 2-4 show theoretical strength and the experimental data of Barre granite, Inada granite and Jinping marble. Figs 5-7 show that comparison of predicted strength and the experimental data of Barre granite, Inada granite and Jinping marble. It is found from Tabs 2-4 and Figs 5-7 that the proposed long-term strength criterion agrees well with experimental data of different rocks.

\begin{tabular}{cccccc}
\hline Rocks & $\begin{array}{c}\text { The strength } \\
\text { parameter(s) }\end{array}$ & $\begin{array}{c}\text { The fitting } \\
\text { strength } \\
\text { parameter(m) }\end{array}$ & $\begin{array}{c}\text { The fitting } \\
\text { strength } \\
\text { parameter } \\
\text { (n) }\end{array}$ & $\begin{array}{c}\text { Long-term uniaxial } \\
\text { compressive } \\
\text { strength }\end{array}$ & Reference \\
Barre granite & 1 & 6.709 & 0.737 & 158 & Kranz [25] \\
Inada granite & 1 & 1.000 & 0.101 & 216 & Maranini and Brignoli [26] \\
Jinping marble & 1 & 12.184 & 18.566 & 80 & Yang et al. [27] \\
\hline
\end{tabular}

Table 1: The fitting strength parameters and uniaxial compressive strength of different rocks. 


\begin{tabular}{|c|c|c|c|c|c|}
\hline$\sigma_{1}(\mathrm{MPa})$ & $\sigma_{2}(\mathrm{MPa})$ & $\sigma_{3}(\mathrm{MPa})$ & $\mathrm{q}(\mathrm{MPa})$ & Pexperimental $(\mathrm{MPa})$ & $\mathrm{p}_{\text {theoretical }}(\mathrm{MPa})$ \\
\hline 280 & 10 & 10 & 270.000 & 100.000 & 99.255 \\
\hline 289 & 10 & 10 & 279.000 & 103.000 & 102.245 \\
\hline 298 & 10 & 10 & 288.000 & 106.000 & 103.266 \\
\hline 301 & 10 & 10 & 291.000 & 107.000 & 104.614 \\
\hline 304 & 10 & 10 & 294.000 & 108.000 & 105.966 \\
\hline 306 & 10 & 10 & 296.000 & 108.667 & 106.869 \\
\hline 312 & 10 & 10 & 302.000 & 110.667 & 109.587 \\
\hline 315 & 10 & 10 & 305.000 & 111.667 & 110.952 \\
\hline 494 & 40 & 40 & 454.000 & 191.333 & 193.264 \\
\hline 468 & 40 & 40 & 428.000 & 182.667 & 180.006 \\
\hline 369 & 20 & 20 & 349.000 & 136.333 & 131.381 \\
\hline 288 & 10 & 10 & 278.000 & 102.667 & 98.800 \\
\hline 247 & 5 & 5 & 242.000 & 85.667 & 85.051 \\
\hline 234 & 5 & 5 & 229.000 & 81.333 & 77.492 \\
\hline 280 & 10 & 10 & 270.000 & 100.000 & 102.255 \\
\hline 289 & 10 & 10 & 279.000 & 103.000 & 99.245 \\
\hline 298 & 10 & 10 & 288.000 & 106.000 & 103.266 \\
\hline 301 & 10 & 10 & 291.000 & 107.000 & 104.614 \\
\hline
\end{tabular}

Table 2: Theoretical strength and the experimental data of Inada granite.

\begin{tabular}{|c|c|c|c|c|c|}
\hline$\sigma_{1}(\mathrm{MPa})$ & $\sigma_{2}(\mathrm{MPa})$ & $\sigma_{3}(\mathrm{MPa})$ & $\mathrm{q}(\mathrm{MPa})$ & $\begin{array}{c}\text { Pexperimental } \\
(\mathrm{MPa})\end{array}$ & ptheoretical $(\mathrm{MPa})$ \\
\hline 162.1 & 0.1 & 160 & 270 & 100.0000 & 106.415 \\
\hline 173.1 & 0.1 & 230 & 279 & 103.0000 & 103.952 \\
\hline 177.1 & 0.1 & 220 & 288 & 106.0000 & 105.514 \\
\hline 179.1 & 0.1 & 110 & 291 & 107.0000 & 101.884 \\
\hline 185.1 & 0.1 & 180 & 294 & 108.0000 & 108.765 \\
\hline 188.1 & 0.1 & 205 & 296 & 108.6667 & 104.870 \\
\hline 196.1 & 0.1 & 235 & 302 & 110.6667 & 109.826 \\
\hline 199.1 & 0.1 & 249 & 305 & 111.6667 & 112.323 \\
\hline 203.1 & 0.1 & 223 & 454 & 191.3333 & 194.439 \\
\hline 262 & 10 & 262 & 428 & 182.6667 & 183.837 \\
\hline 343 & 25 & 100 & 349 & 136.3333 & 135.572 \\
\hline 348 & 53 & 350 & 278 & 102.6667 & 107.943 \\
\hline
\end{tabular}

Table 3: Theoretical strength and the experimental data of Barre granite. 


\begin{tabular}{cccccc}
\hline$\sigma_{1}(\mathrm{MPa})$ & $\sigma_{2}(\mathrm{MPa})$ & $\sigma_{3}(\mathrm{MPa})$ & $\mathrm{q}(\mathrm{MPa})$ & $\begin{array}{c}\text { pexperimental } \\
(\mathrm{MPa})\end{array}$ & ptheoretical $^{(\mathrm{MPa})}$ \\
110 & 20 & 12 & 94.255 & 47.333 & 45.757 \\
120 & 20 & 14 & 103.131 & 51.333 & 52.277 \\
130 & 20 & 18 & 111.014 & 56.000 & 58.335 \\
140 & 20 & 20 & 120.000 & 60.000 & 59.550 \\
150 & 20 & 20 & 130.000 & 63.333 & 63.965 \\
160 & 20 & 20 & 140.000 & 66.667 & 65.786 \\
170 & 20 & 150.000 & 70.000 & 72.013 \\
155 & 35 & 120.000 & 75.000 & 75.550 \\
165 & 35 & 130.000 & 78.333 & 77.965 \\
175 & 35 & 140.000 & 81.667 & 82.786 \\
185 & 35 & 150.000 & 85.000 & 86.013 \\
195 & 35 & 160.000 & 88.333 & 89.647 \\
205 & 35 & 35 & 170.000 & 91.667 & 91.687 \\
215 & 35 & 35 & 180.000 & 95.000 & 92.134 \\
180 & 50 & 35 & 132.571 & 91.667 & 96.193 \\
190 & 50 & 45 & 141.524 & 95.667 & 94.165 \\
200 & 50 & 47 & 152.040 & 98.667 & 93.945 \\
210 & 50 & 46 & 160.000 & 103.333 & 101.647 \\
220 & 50 & 50 & 170.000 & 106.667 & 101.687 \\
230 & 50 & 50 & 180.000 & 110.000 & 112.134 \\
\hline & & 50 & & & \\
\hline
\end{tabular}

Table 4: Theoretical strength and the experimental data of Jinping marble.

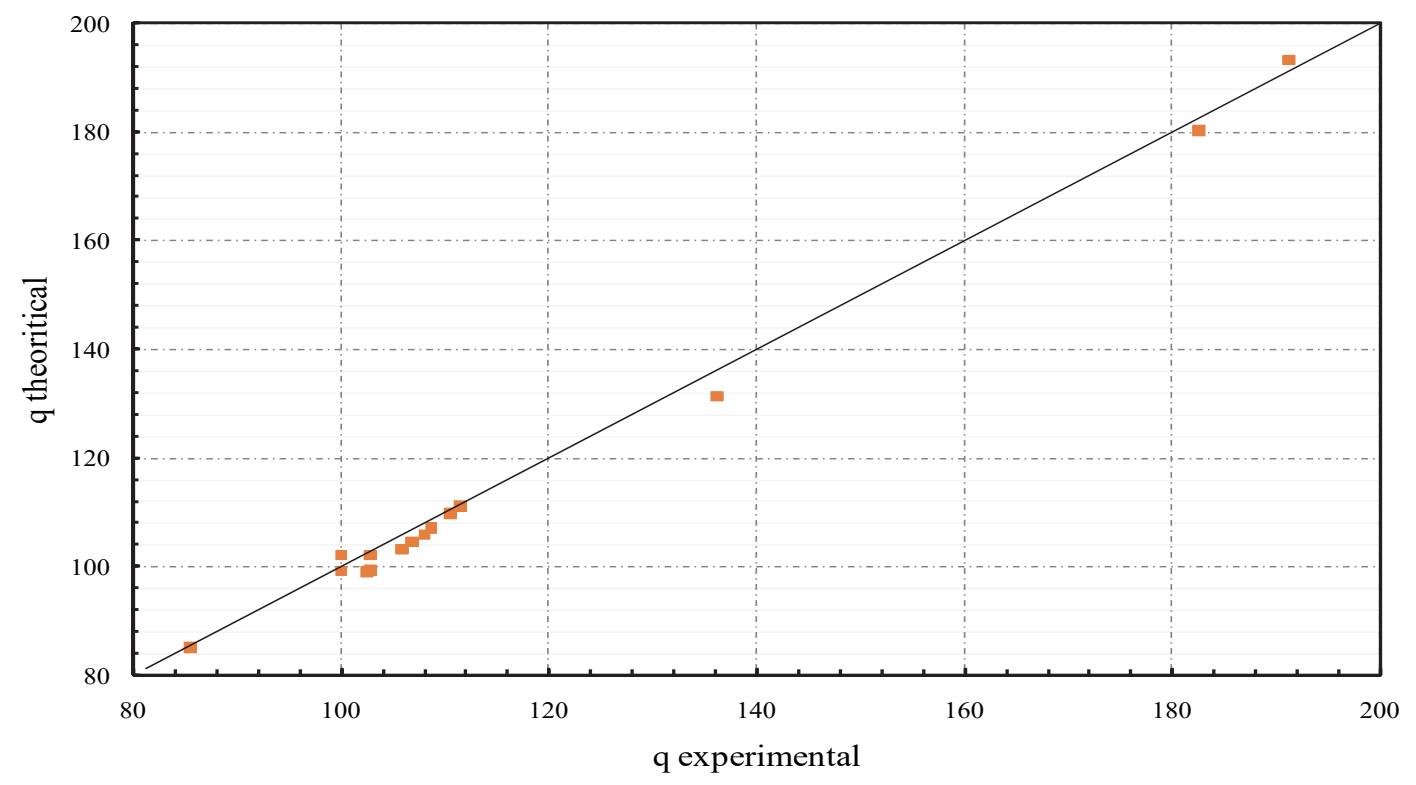

Figure 5: Comparison of predicted strength and the experimental data of Inada granite. 


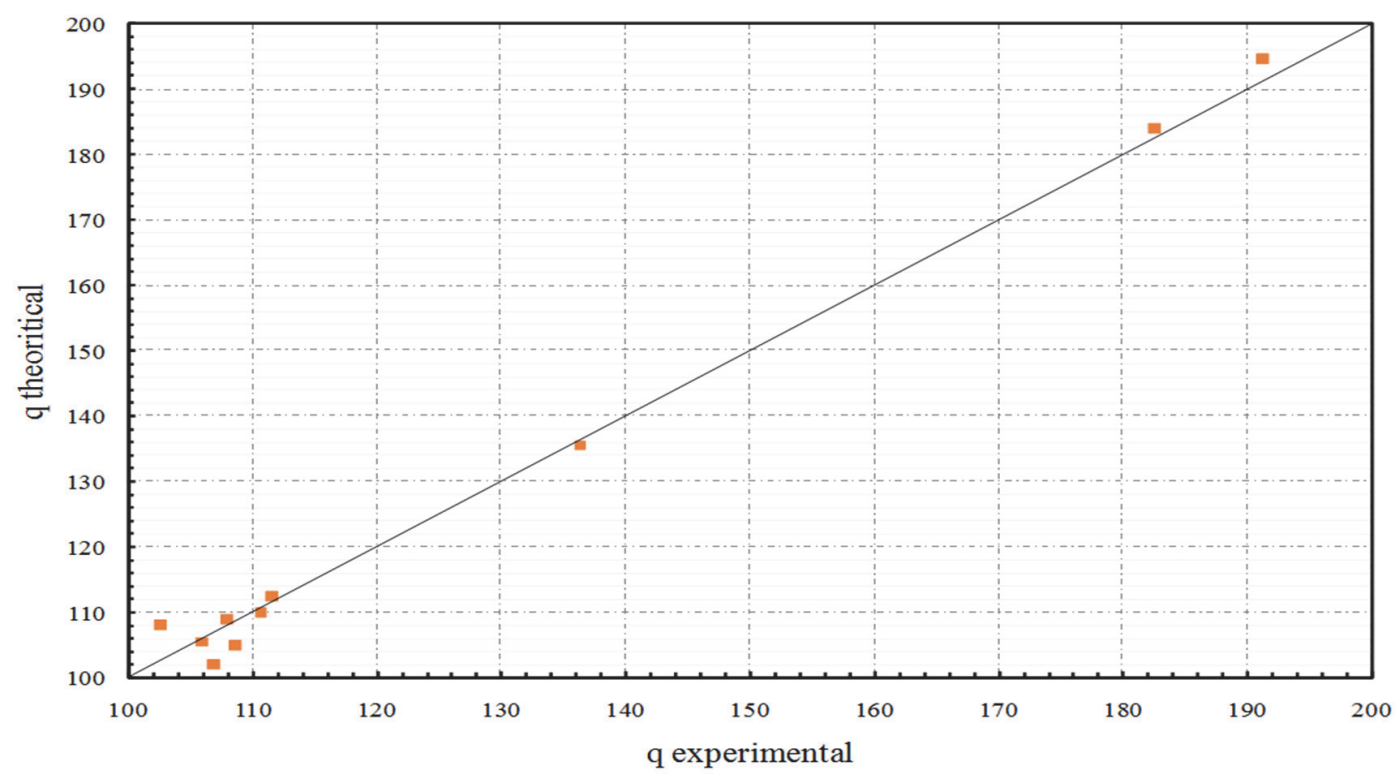

Figure 6: Comparison of predicted strength and the experimental data of Barre granite.

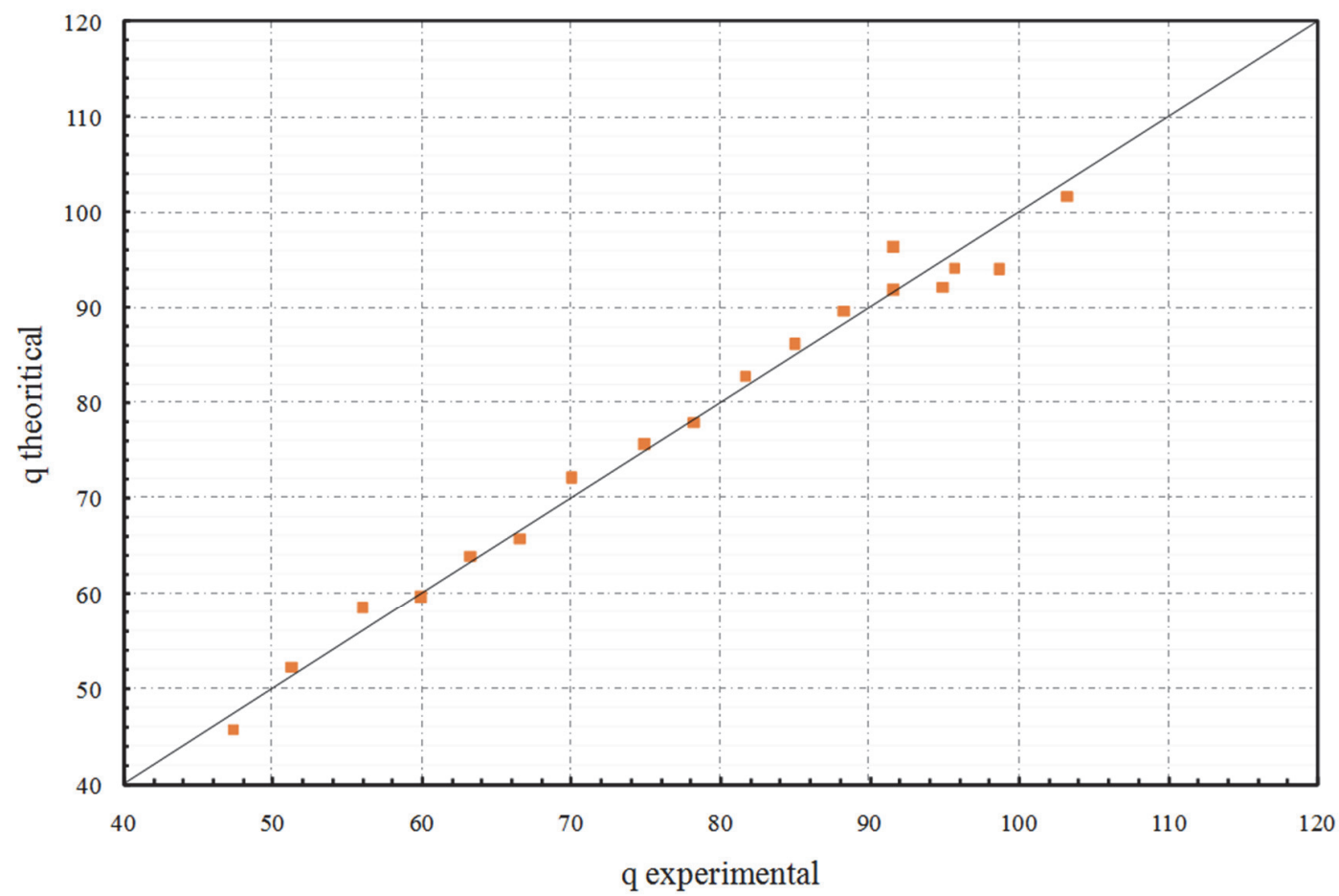

Figure 7: Comparison of predicted strength and the experimental data of Jinping marble

\section{DISCUSSIONS AND CONCLUSIONS}

I

$\mathrm{n}$ this paper, Burgers model with the characteristics of instantaneous elastic deformation, primary creep and steadyrate creep is applied to investigate creep fracture behaviors of penny-shaped microcracks. Mode II stress intensity factor at tips of three-dimensional penny-shaped microcracks embedded in Burgers viscoelastic rock matrix is derived. The orientation angle of micro-failure in Burgers viscoelastic rocks is defined. A novel micromechanics-based threedimensional long-term strength criterion is proposed to investigate effects of time and the intermediate principal stress on 
the creep failure of rocks. By comparison with the previous experimental results, it is found that the novel micromechanics-based three-dimensional long-term strength criterion is in good agreement with experimental data.

\section{ACKNOWLEDGMENTS}

7 his work was supported by the National Natural Science Foundation of China (Nos. 51325903 and 51679017), project 973 (Grant no. 2014CB046903), Graduate Scientific Research and Innovation foundation of Chongqing, China (Grant No. CYB16012), Open Research Fund Program of Hunan Provincial Key Laboratory of Geotechnical Engineering for Stability Control and Health Monitoring, Natural Science Foundation Project of CQ CSTC (Nos. cstc2013kjrc-ljrccj0001 and cstc2013jcyjys0005) and Research fund by the Doctoral Program of Higher Education of China(No.20130191110037).

\section{REFERENCES}

[1] Baud, P. and Meredith, P. G., (1997). Damage accumulation during triaxial creep of darley dale sandstone from pore volumometry and acoustic emission, Int. J. Rock Mech. Min. Sci. 34, pp. 24.e1-24.e10.

[2] Heap, M. J., Baud, P., Meredith, P. G., Bell A. F. and Main, I.G., (2009). Time-dependent brittle creep in Darley Dale sandstone, J. Geophys. Res.D: Atmos, 114, pp. 1-22.

[3] Heap, M. J., Baud, P., Meredith, P. G., Vinciguerra, S., Bell, A. F. and Main, (2011). I.G., Brittle creep in basalt and its application to time-dependent volcano deformation, Earth Planet Sci. Lett., 307, pp. 71-82.

[4] Li, Y. and Xia, C., (2000). Time-dependent tests on intact rocks in uniaxial compression, Int. J. Rock Mech. Min. Sci., 37 , pp. 467-475.

[5] Shin, K., Okubo, S., Fukui, K. and Hashiba, K., (2005). Variation in strength and creep life of six Japanese rocks, Int. J. Rock Mech. Min. Sci., 42, pp. 251-260.

[6] Aubertin, M., Li, L. and Simon, R., (2000). A multiaxial stress criterion for short- and long-term strength of isotropic rock media, Int. J. Rock Mech. Min. Sci., 37, pp. 1169-1193.

[7] Amitrano, D. and Helmstetter, A., Brittle creep, damage and time to failure in rocks, (2006). J. Geophys. Res. B: Solid Earth, 111, pp. 335-360.

[8] Bahaaddini, M., Hagan, P.-C., Mitra, R. and Hebblewhite, B.-K., (2015). Numerical Study of the Mechanical Behavior of Nonpersistent Jointed Rock Masses, Int. J. Geomech., 10.1061/(ASCE)GM.1943-5622.0000510, 04015035.

[9] Barla, M. and Beer, G., (2012). Special Issue on Advances in Modeling Rock Engineering Problems, Int. J. Geomech., 12, pp. 617-617.

[10] Yang, Q., Chen, X. and Zhou, W. Y., (2005). On the structure of anisotropic damage yield criteria, Mech. Mater., 37, pp. 1049-1058.

[11]Zhou, X. P., Bi J. and Qian, Q. H., (2015). Numerical simulation of crack growth and coalescence in rock-like materials containing multiple pre-existing flaws, Rock Mech. and Rock Eng., 48, pp. 1097-1114.

[12]Zuo, J. P., Li, H. T., Xie, H. P., Ju, Y. and Peng, S. P., (2008). A nonlinear strength criterion for rock-like materials based on fracture mechanics, Int. J. Rock Mech. Min. Sci., 45, pp. 594-599.

[13] Al-Ajmi, A. M. and Zimmerman, R. W., (2005). Relation between the mogi and the coulomb failure criteria, Int. J. Rock Mech. Min. Sci. 42, pp. 431-439.

[14] Paterson, M. S. and Wong, T. F., (2005). Experimental rock deformation - the brittle field, Mineral Mag., 43, pp. 163186.

[15] Yu, S. W. and Feng, X. Q., (1995). A micromechanics-based damage model for microcrack-weakened brittle solids, Mech. Mater., 20, pp. 59-76.

[16] Tada, H., (1973). The stress analysis of cracks handbook, Stress Analysis of Cracks Handbook, 91, pp. 614.

[17] Yi, S. M. and Zhu, Z.D., (2005). Introduction to damage mechanics of crack-weakened rock masses, Science Press, Beijing.

[18] Zhou, Z. B., (1983). Stress intensity factors for creep fracture and their application, Acta Mech. Solida Sin., 1, pp. 100104.

[19] Erdogan, F. and, Sih, G. C., (1963). On the crack extension in plates under plane loading and transverse shear, J. Basic Eng. Asme, 85, pp. 527. 
[20] Aboudi, J. and Benveniste, Y., (1987). The effective moduli of cracked bodies in plane deformations, Eng. Fract. Mech., 26, pp. 171-184.

[21] Budiansky, B. and O'Connell, R. J., (1976). Elastic moduli of a cracked solid 论. Int. J. Solids Struct., 12, pp. 81-97.

[22] Kachanov, M., (1992). Effective elastic properties of cracked solids: critical review of some basic concepts, Appl. Mech. Rev., 45, pp. 304-335.

[23] Paterson, M. S. and Wong, T. F., (2005). Experimental rock deformation - the brittle field, Mineral Mag., 43, pp. 163186.

[24] Brady, B. T., (1969). A statistical theory of brittle fracture for rock materials Part II—brittle failure under homogeneous triaxial states of stress, Int. J. Rock Mech. Min. Sci. Geomech. Abstr., 6, pp. 285-300.

[25] Kranz, R. L., (1980). The effects of confining pressure and stress difference on static fatigue of granite, J. Geophys. Res.D: Atmos, 85, pp. 1854-1866.

[26] Maranini, E. and Brignoli, M., (1999). Creep behaviour of a weak rock. experimental characterization, Int. J. Rock Mech. Min. Sci., 36, pp. 127-138.

[27] Yang, S. Q., Xu, P., Ranjith, P. G., Chen, G. F. and Jing, H. W., (2015). Evaluation of creep mechanical behavior of deep-buried marble under triaxial cyclic loading, Arab. J. Geosci., pp. 81-16. 